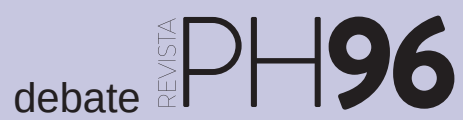

a debate Memoria democrática en la construcción de la historia y el patrimonio

| coordina Josefina Cuesta Bustillo

\title{
El olvido está lleno de memorias: memorias y patrimonios de nuestro pasado reciente
}

Andrea Moreno Martín | gestora de patrimonio cultural en el Ayuntamiento de Quart de Poblet

URL de la contribución <www.iaph.es/revistaph/index.php/revistaph/article/view/4309>

"Hay que recuperar, mantener y transmitir la memoria histórica porque se empieza por el olvido y se acaba por la indiferencia..." J. Saramago

Aunque parezca evidente, merece la pena matizar que no es lo mismo la historia que la memoria ${ }^{1}$. Sin embargo, en la naturaleza de esta última, el pasado histórico y el patrimonio son un elemento clave; pues en los procesos de construcción de las memorias, igual que ocurre con los patrimonios, el quid de la cuestión se centra en concretar qué merece o no ser recordado y quién tiene la potestad y la autoridad de decidir qué se olvida y qué se recuerda (CANDAU, 2002; RICOEUR, 2003; JELIN, 2012).

Con el paso del tiempo, los discursos políticos de la historia se reformulan o incluso se alteran. $Y$ aunque los hechos y la historia son los que son, a menudo la historia, como dijo Winston Churchill, la escriben los vencedores. Así sucedió en España, cuando los golpistas del 1936 acabaron con la legalidad y la democracia republicana y, autoproclamados "los nacionales", liberaron a la patria. En esa nueva España franquista, el final de la guerra no trajo la paz sino la victoria y el nacionalcatolicismo. Una victoria que durante cuatro décadas fue la esencia de las políticas de identidad, memoria y represión de la dictadura, cimentada en los tres pilares del régimen: el ejército, la iglesia y el Movimiento Nacional.

La memoria de esa "Nueva España" se construyó bajo los criterios antidemocráticos del franquismo y perduró como verdad/memoria de estado a través del adoctrinamiento, la censura, la violencia y la instrumentación del pasado y del patrimonio. Una memoria no de paz sino de victoria, que elaboró un nuevo discurso histórico de autolegitimación basado en una España de vencedores y vencidos.

Esa memoria franquista mandó al olvido ( $\mathrm{y}$ al paredón) a todo símbolo, recuerdo o memoria de la democracia republicana anterior y se convirtió en el credo de una España que vivió sometida al Caudillo durante los más de 14.000 días en que reinó el Generalísimo. Sin embargo, con la muerte del dictador en 1975, el franquismo sociológico no murió o, al menos, no lo hizo su memoria. Prueba de ello son algunas de las casuísticas que aún vivimos en la España de 2018 con temas como la exhumación de Franco, la retirada de la simbología, las fosas, las cunetas, los juicios... Y, en definitiva, ese debate mediático, social y político sobre la necesidad o no de las políticas públicas de memoria.

Resulta anacrónico que en la España actual aún perdure ese "no tocar peligro de muerte" en lo referente a Franco y la dictadura ${ }^{2}$. Huelga decir que la coyuntura actual debe ser entendida partiendo del status quo y la memoria que estableció la Transición como una suerte de pacto entre caballeros ${ }^{3}$. Pues como explica Vinyes, "el mito fundacional de la democracia" se amparaba en la seguridad y la convivencia para justificar la impunidad equitativa y la reconciliación como ideología de estado (VINYES, 2011: 11-30).

En su acepción más amplia (y no únicamente vinculada al franquismo), la memoria es una acción para la reparación y para paliar la invisibilización histórica y la discriminación de hechos, colectivos y/o personas, que debe refutar discursos políticos que defiendan una única verdad oficial. En este sentido, la memoria como constructo deber ser pública, social y democrática; sin pretensión de sustituir a la historia como discurso científico. 


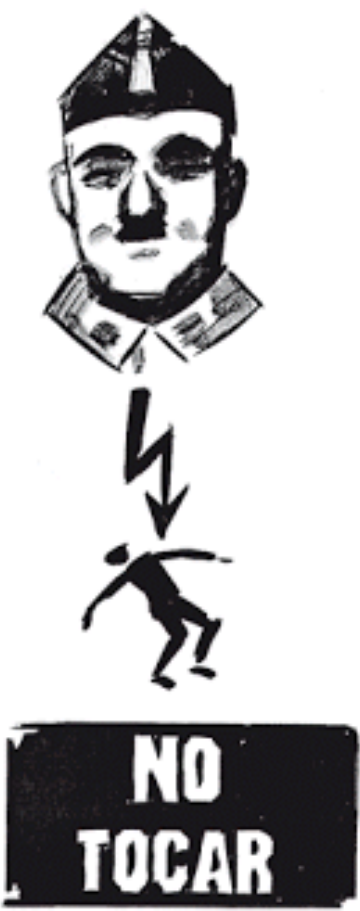

Viñetas para la memoria: "No tocar" | viñeta El Roto@ (El País, 6 de marzo de 2010)

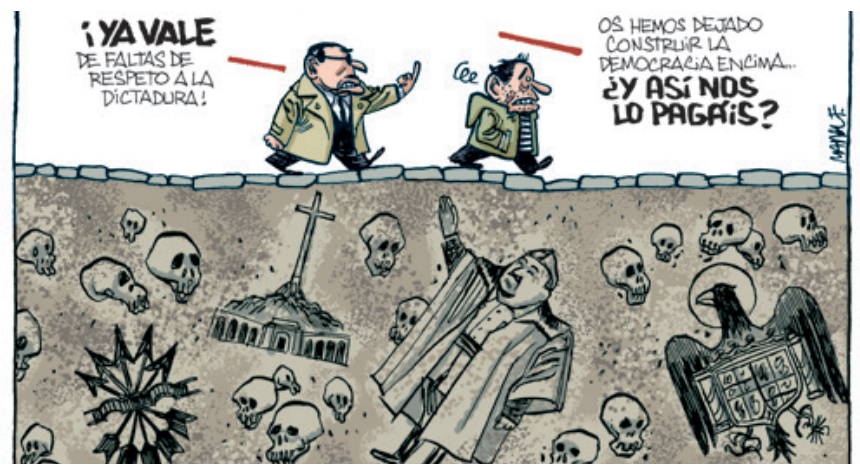

Viñetas para la memoria: "Un respeto" | viñeta Manel Fontdevila@ (Público, 1 de diciembre de 2011)

El dilema al que nos enfrentamos se centra entonces en si, como sociedad y como estado, somos capaces de renunciar a esa memoria heredada para poder construir nuestra propia memoria sobre el pasado reciente. Un proceso complejo pues la memoria democrática solo puede ser una memoria de memorias y de patrimonios.
No se trata de instaurar una única memoria nacional y de estado por encima de "las otras", sino de construir memorias desde abajo, que respondan a criterios democráticos y que sean patrimonializadas por la sociedad.

El matiz es importante y necesario: nuestra memoria no puede ser vehemente ni consentidora de ciertas nostalgias. La piedra fundacional de la memoria democrática en España debe asentarse en una ecuación sencilla pero que no todo el mundo asume: la guerra se produjo en España por un golpe de estado contra un régimen democrático y acabó con la instauración de una dictadura militar. Resulta evidente, pues, que las loas a los golpistas y la edulcoración de la dictadura no tienen cabida en un estado y una sociedad democrática. $Y$ en este tema, no hay debate posible.

No es cuestión de venganza, de honrar/olvidar "a los tuyos o a los míos", sino todo lo contrario. Paradójicamente, olvidar como opción "personal" de memoria no es en sí un problema, pues el olvido está lleno de memoria (como escribió Benedetti) y porque por largo que sea ese olvido, la historia no desaparece. El problema viene cuando el olvido se instaura como punto de partida de las políticas públicas y éste generaliza e institucionaliza la indiferencia, el desconocimiento y la uniformización de la memoria.

La memoria no debe ser solo discurso político de mera militancia sino una praxis y un derecho civil: una acción colectiva entre la ciudadanía, los profesionales y las instituciones. Se trata de reflexionar, haciendo partícipe a la ciudadanía, sobre nuestra historia (nuestro pasado y nuestro presente). Porque si la memoria se puede elegir, se puede construir, debemos ser parte activa en este proceso y generar una memoria colectiva democrática, inclusiva e intergeneracional.

Por consiguiente, el proceso debe ofrecer herramientas y vías para que la ciudadanía genere su propia opinión y potenciar así el pensamiento crítico, cívico y participativo; en un proceso de empoderamiento donde las personas asuman las decisiones y los recursos (MORENO; 


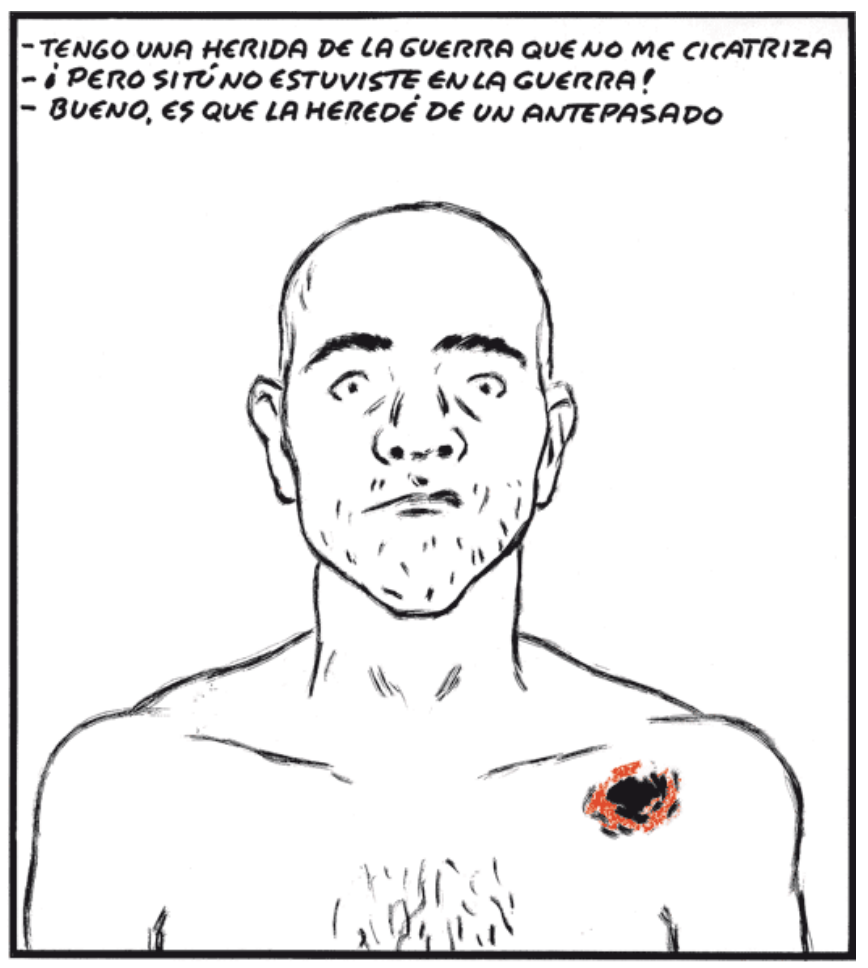

Viñetas para la memoria: "Tengo una herida de la guerra..." | viñeta El Roto@ (El País, 21 de abril de 2010)

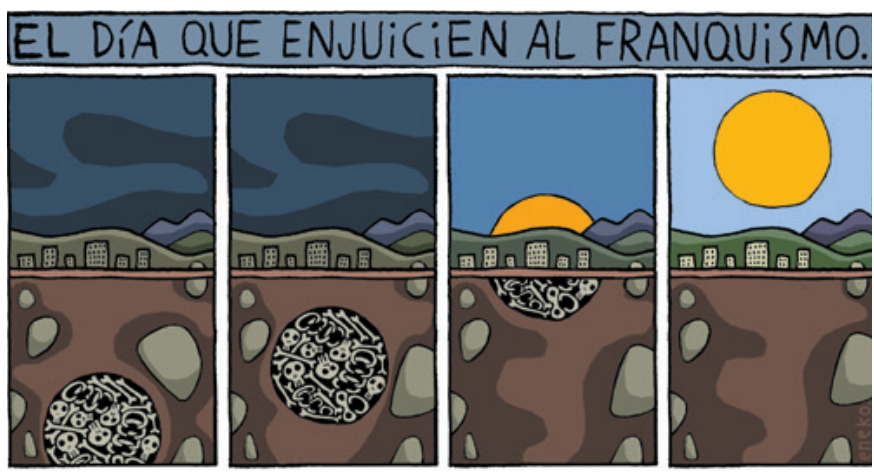

Viñetas para la memoria: "El día que enjuicien al franquismo" | viñeta Eneko@ (20 minutos, 29 de febrero de 2012)

NúÑEZ, 2016: 171-179). Y, en este sentido, la puesta en valor de espacios y lugares, la recuperación de testimonios, del patrimonio gráfico y documental y la cultura material, deviene crucial para divulgar y explicar qué fueron y supusieron para España un golpe de estado, una guerra y 40 años de dictadura nacionalcatolicista.
Es entonces tiempo de exhumar, dar luz y poner voz a nuestra historia desde la academia y la profesionalidad, pero también desde la calle y desde las instituciones a través de políticas públicas de memoria. Pues solo si somos capaces de patrimonializar esas memorias y esos conflictos, construiremos una memoria democrática ciudadana y evitaremos la "gentrificación ${ }^{4}$ memorial" de la que Vinyes nos advierte.

\section{NOTAS}

1. La historia es una disciplina científica que se centra en el estudio, análisis y explicación de los hechos y acontecimientos relativos a nuestro pasado, ya sea éste remoto o reciente. Los hechos son los que son; no se pueden cambiar. Lo que sí suele cambiar (desafortunadamente) es el uso que se puede hacer de ellos. La memoria, por contra, igual que el patrimonio, no existe; es un constructo social, cultural y político que se puede elegir y definir.

2.No obstante, hay que matizar que los nuevos marcos legislativos van dibujando un horizonte inédito en la gestión de los temas de memoria por parte del Estado y de los gobiernos autonómicos (DE LA CUESTA; ODRIOZOLA, 2018).

3. Y como muestra, solo citar las leyes de Reforma Política y de Amnistía de 1977 (ESCUDERO, 2013: 322-326).

4. Neologismo inglés acuñado desde la sociología y la geografía, que en el caso de la memoria describiría un proceso de transformación de las memorias diversas en un único relato memorial, construido desde arriba y que rechaza la naturaleza conflictiva de nuestro pasado reciente (VINYES, 2015: 34-35)

\section{BIBLIOGRAFÍA}

- CANDAU, J. (2002) Antropología de la memoria. Buenos Aires: Ediciones Nueva Visión, 2002 (Claves y Problemas) 
a debate Memoria democrática en la construcción de la historia y el patrimonio

| coordina Josefina Cuesta Bustillo

- De la CUESTA, J. L.; ODRIOZOLA, M. (2018) Marco normativo de la memoria histórica en España: legislación estatal y autonómica. Revista Electrónica de Ciencia Penal y Criminología [en línea], n. ${ }^{\circ} 20,2018$, pp. 1-38<http://criminet. ugr.es/recpc/20/recpc20-08.pdf> [Consulta: 13/11/2018]

- ESCUDERO, R. (2013) Jaque a la transición: análisis del proceso de recuperación de la memoria histórica. Anuario de filosofía del derecho, n. ${ }^{\circ} 29,2013$, pp. 319-340

- ESCUDERO, R. (coord.) (2011) Diccionario de memoria histórica: conceptos contra el olvido. Madrid: Libros de la Catarata, 2011

- JELIN, E. (2012) Los trabajos de la memoria. 2a ed. Lima: Instituto de Estudios Peruanos, 2012

- MORENO, A.; NÚÑEZ, L. (2016) La cultura material del franquismo. Deconstruyendo la memoria histórica. La Linde. Revista digital de arqueología profesional [en línea], 7-2016, pp. 152-181. <http://lalindearqueologia.com/la-culturamaterial-del-franquismo/> [Consulta: 13/11/2018]

- RICOEUR, P. (2003) La memoria, la historia, el olvido. Madrid: Trotta, 2003

- VINYES, R. (2011) Asalto a la memoria. Impunidades y reconciliaciones, símbolos y éticas. Barcelona: Los libros del lince, 2011

- VINYES, R. (2015) Los usos públicos del pasado en Europa: hacia una memoria sincrética. Años 90 , vol. 22, n. ${ }^{\circ} 42,2015$, pp. 21-51 